\title{
Public Perception of Dental Health Care during the Covid-19 Pandemic using Teledentistry Surveys
}

\section{Burhanuddin Daeng Pasiga*}

Department of Dental Public Health, Faculty of Dentistry, Hasanuddin University, Makassar, Indonesia. *Corresponding Author: Burhanuddin Daeng Pasiga, Department of Dental Public Health, Faculty of Dentistry, Hasanuddin University, Makassar, Indonesia.

\section{Abstract}

Background: The COVID-19 problem is a world problem and affects all aspects of human life including dental care.

Objective: To find out the public perception of dental care during the pandemic with online interviews using the Teledentistry Survey..

Methods: The researcher determines the sample to be interviewed using the TELKOMSEL provider and chooses a number with the Sulawesi region code, the first number is chosen as the sample number 0821-8801-0295, the next sample is a multiple of 5. This study has received approval from the Ethics Commission of the Faculty of Dentistry, University Hasanuddin with number: \#UH 17120346.

Results: There were $88 \%$ of the samples experiencing dental health problems during the COVID-19 pandemic, namely $24 \%$ sprue and $14 \%$ toothache. The actions taken by respondents to overcome dental health problems were $46 \%$ self-medicating, $18 \%$ online consultation with dentists, $14 \%$ untreated, and $12 \%$ going to a dental clinic. Their perception that dental health care can cause transmission of the virus as much as $64 \%$ and they are afraid to come to the dentist during the pandemic as much as $88 \%$. Overall, only $71.5 \%$ of the public knew about dental care problems during the pandemic.

Conclusion: Public perception of dental care knowledge during the COVID-19 pandemic is quite good

Keyword: Dental Health Care; COVID-19; Teledentistry

\section{INTRODUCTION}

Coronavirus has spread rapidly around the world since it had been first reported in China in December 2019 [1] [2]. Supported data presented within the mass media (Babe), in August 2020 data from around the world who were positive for COVID-19 were $>25$ million people, 845925 people died and 17491 people recovered while in Indonesia data as of August 30, 2020, there have been 169195 people positive for COVID-19, 7261 died and 12280 recovered. The Health Organization (WHO) announced that the COVID19 outbreak had become a public health emergency of international concern on January 31, 2020,2, and was categorized as an epidemic on March 11, 2020 [3] [4]. Virus detection is often done through saliva, body fluids, faces. The virus is spread through close contact between people, mainly through respiratory droplets [5]. Additionally, when people touch objects contaminated by infectious droplets, then touch their mouth, nose, or eye, the virus is often transmitted. Thus, several countries have developed high standards for viral transmission prevention measures, namely social isolation to avoid the rapid spread of the virus, protection of the elderly and patients with chronic diseases and enhancing low immunity with vitamin C or vitamin E drinks. The obstacles faced by the 
Public Perception of Dental Health Care during the Covid-19 Pandemic using Teledentistry Surveys

community in completing care during the COVID19 pandemic where fear and worry about contracting the COVID19 virus. Albeit people needs care [6]. The public already understands that care may be a high risk for the transmission of COVID19 because they know that dental procedures produce aerosols and splashes which may contain large amounts of saliva or blood from the patient, and thus, carry a risk of transmission of the virus [7] [8] [9] [10]. Emergency dental services are vital for the community during the COVID-19 pandemic, like life-threatening conditions, like an uncontrolled oral tissue bleeding, head and neck infections, or facial trauma which will endanger the patient's airway, patients with severe toothaches that aren't are often controlled with analgesics or patients with dental trauma or other medical emergencies. ADA (2020) developed guidelines on dental emergency and non-emergency dental procedures, which include an inclusive list of emergency care aimed toward minimizing pain, preventing infection, and reducing discomfort [11] [12]. Local governments are required to plan, implement, and evaluate programs supported adherence to health promotion ideals, aware of community needs [9]. Telemedicine or Teledentistry survey methods can help determine quickly the status of public oral health [13] [14] [15] [16]. The telemedicine or Teledentistry survey method using telephone surveys was developed by the Behavioural Risk Factor closed-circuit television (BRFSS) [17], which was developed by the Canters for disease control and prevention (CDC) and administered by the NY Department of Health and in some countries, it's already using this method to seek out [17]. Some dental health behaviors during the COVID19 pandemic, the public knows a lot about dental health problems through the media which informs about the dangers of the transmission of the Coronavirus both in general and comprehensive care [18]. Some involve limiting care in some health service units apart from emergencies to scale back the danger of transmission of COVID-19 through care. Information about the straightforward transmission of COVID-19 makes people scared of being infected with COVID-19, so that they are reluctant to travel to health service providers, including dental health services, and eventually decide not to perform or postpone care during the COVID-19 period [5] [19].

\section{Material ANd Methods}

\section{Design Research}

This type of research is observational with crosssectional study design. This research was conducted in June 2020. The population of this research is a mobile phone user with a number from telkomsel provider for South Sulawesi zone. Sampling by selecting the first sample where researchers freely choose the new TELKOMSEL number with sulawesi region code number obtained number 0821-8801-0295, the next sample is the researcher determines with a multiple of 5 , starting from the last digit number, which is 0295. The number of samples is 295 . The study has received approval from the Ethics Commission of the Hasanuddin University Faculty of Dentistry with the number: \#UH 17120346

\section{Research Exclusion Criteria}

1. Individuals under 18 years aged

2. Individuals who don't want to be interviewed

3. Individuals with Telkomsel telephone numbers can't be contacted.

4. Individual who changes the topic during the interview.

\section{Research Instruments}

The instrument during this study was a questionnaire used for interview material with a guided system for 15 minutes.. This questionnaire consists of 10 questions, including questions about sociodemographic (age, gender, current education, occupation) and questions about public knowledge about dental problems during the COVID-19 pandemic and community suggestions for health workers in the field of dental health. The questions are as follows:

1. Have you ever experienced dental health problems or have you ever experienced a problem mouth during the COVID-19 pandemic?

2. What are the dental and oral health problems that you (i) experience during the COVID-19 pandemic? 
Public Perception of Dental Health Care during the Covid-19 Pandemic using Teledentistry Surveys

3. Do you feel afraid to go to the clinic or practice dentist during the COVID-19 pandemic?

4. In the opinion of you, can someone get the Coronavirus if they do dental care during the COVID-19 pandemic at a clinic or dentist's practice?Coronavirus when performing dental care during a pandemic COVID-19 in a clinic or dentist?

5. Have you ever received any information about the patient who has performed dental care with the Coronavirus?

6. According to your opinion, what makes a person get contracted the Coronavirus while doing dental work in a clinic or a dentist's practice

7. The source of information from where you got that care can teeth be infected by the Coronavirus?

8. The dentist performs dental care in accordance with the Standard Operating Procedure, did you still not go to a dental doctor during the pandemic, even though your oral health problems?

Tabel1. Sample characteristics $(n=50)$
9. If you have dental and oral health problems during a pandemic, what are the actions taken?

10. Advice given to dentists in carrying out treatment teeth during the COVID-19 pandemic?

The sample was contacted via a smartphone, the first said "Greetings", then the aims and objectives of the study and asked the respondent's willingness to be interviewed. If the respondent agrees, an interview is carried out for 15 minutes.

\section{RESUlt}

The survey results were obtained from 295 Telkomsel number users who were contacted, there were 181 (61\%) inactive number, 41 (13\%) unanswered number, $23(7 \%)$ did not want to be interviewed, so the sample interviewed was 50 respondents.

Table 1, shows that the average age of the respondents $=39.54$ years, with the highest gender being male as much as $62 \%$ with the most undergraduate education level of $46 \%$, followed by high school $=32 \%$. The response that has a job is $50 \%, 26 \%$ does not work and as a student or student is $24 \%$.

\begin{tabular}{|l|l|l|l|}
\hline \multicolumn{1}{|c|}{ Sample characteristics } & n & $\mathbf{\%}$ & Mean \\
\hline Age & & & 39,54 \\
\hline Gender & & & \\
\hline$-\quad$ Male & 31 & $62 \%$ & \\
\hline$-\quad$ Women & 19 & $38 \%$ & \\
\hline Education & & & \\
\hline$-\quad$ High school & 16 & $32 \%$ & \\
\hline$-\quad$ Diploma & 5 & $10 \%$ & \\
\hline$-\quad$ Bachelor & 23 & $46 \%$ & \\
\hline$-\quad$ Masters & 6 & $12 \%$ & \\
\hline Job status & & & \\
\hline$-\quad$ Student / Student & 12 & $24 \%$ & \\
\hline$-\quad$ Civil Servants / State Company Servants & 10 & $20 \%$ & \\
\hline$-\quad$ General employees & 6 & $12 \%$ & \\
\hline$-\quad$ No work / no permanent job & 10 & $20 \%$ & \\
\hline$-\quad$ Entrepreneur / Trader & 9 & $18 \%$ & \\
\hline$-\quad$ Other work & 3 & $6 \%$ & \\
\hline
\end{tabular}

Table 2, shows that $88 \%$ of respondents experienced dental health during the COVID-19 pandemic. Most of the problem is canker sores $24 \%$, then $14 \%$ cavities. The actions taken by respondents to treat dental health problems were $46 \%$ self-medicating, $18 \%$ online consultation with dentists, $14 \%$ untreated, and $12 \%$ going to a dental clinic. 
Public Perception of Dental Health Care during the Covid-19 Pandemic using Teledentistry Surveys

Table2. Distribution of dental and oral health problems experienced by respondents as well as dental care carried out during the COVID-19 pandemic

\begin{tabular}{|c|c|}
\hline Question & $\%$ \\
\hline $\begin{array}{l}\text { Have you ever experienced dental health } \\
\text { problems or have you (i) ever } \\
\text { experienced a problem mouth during the } \\
\text { COVID-19 pandemic? }\end{array}$ & $\begin{array}{ccc}\text { No } & 12 \% & \\
\text { Yes } & & \\
0 \% & & 50 \%\end{array}$ \\
\hline $\begin{array}{l}\text { What are the dental and oral health } \\
\text { problems that you (i) experience during } \\
\text { the COVID-19 pandemic? }\end{array}$ & \begin{tabular}{r|r} 
Grow new teeth & $8 \%$ \\
Loose teeth & $8 \%$ \\
Remaining tooth... & $8 \%$ \\
Swollen gums & $12 \%$ \\
Bad breath/tartar & $6 \%$ \\
Bleeding gums & $6 \%$ \\
Oral thrush/sores & $10 \%$ \\
Cavities/... & $14 \%$
\end{tabular} \\
\hline $\begin{array}{l}\text { If you experience oral health problems } \\
\text { during a pandemic, what actions can you } \\
\text { take? }\end{array}$ & 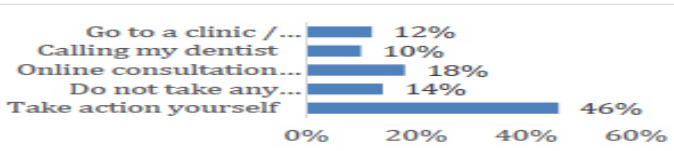 \\
\hline
\end{tabular}

Table 3, shows the majority of answers who answered "Yes" that a person can be infected with the Coronavirus if they do dental work during a pandemic in a dental clinic / practice as much as $62 \%$. Those who answered that someone

could contract the Coronavirus if they did dental work that produced aerosols (water droplets in the air) as much as 34\%, those who answered touching equipment or the environment around the practice place were $12 \%$.

Table3. Distribution of sources of information obtained by respondents regarding the risk of transmission of COVID-19 through dental care.

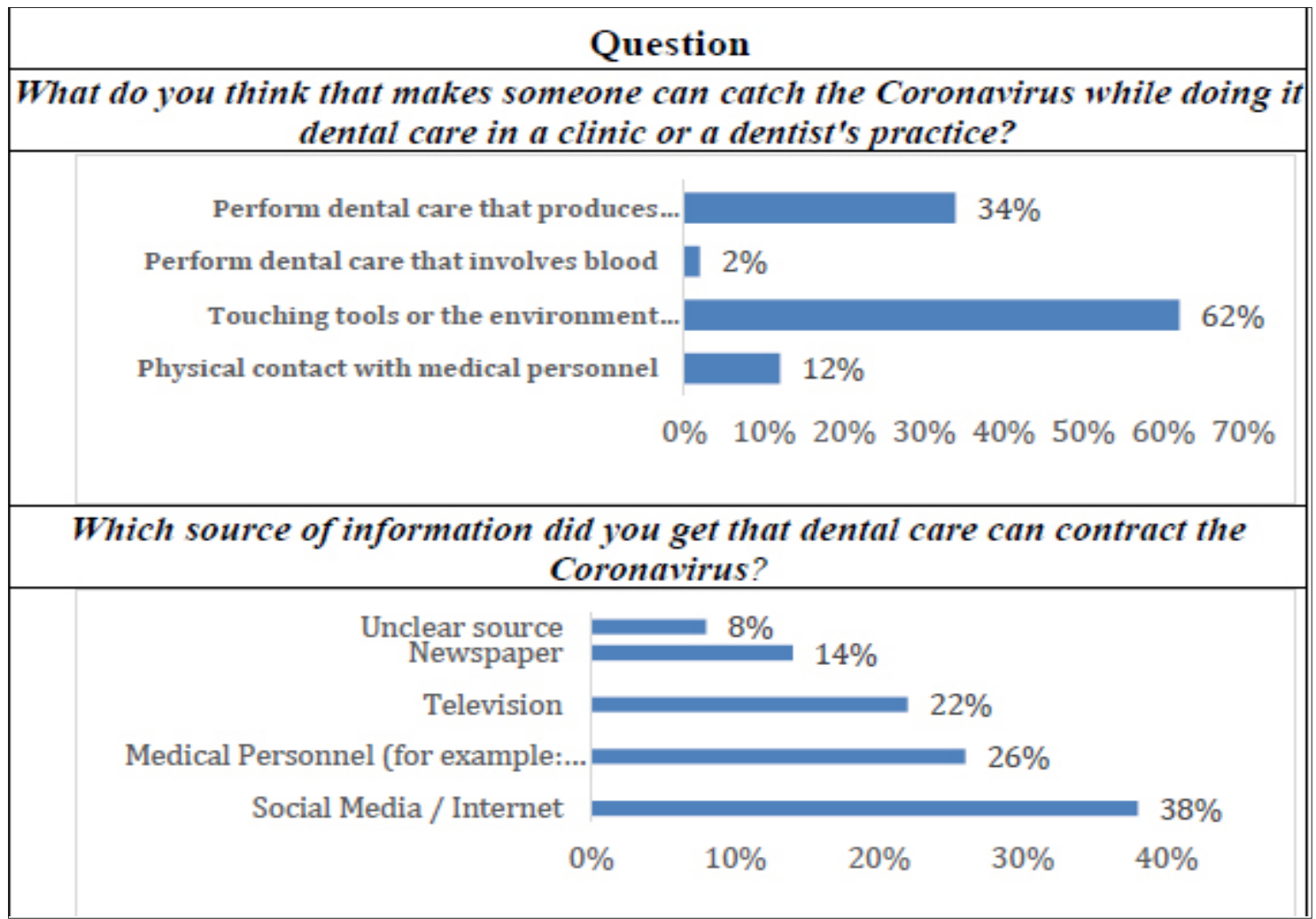

** There were several respondents who chose more than one answer option so that the percentage of "Information Sources" was more than 100\%.

The source of information obtained by respondents that there were consequences for dental care during the COVID-19 pandemic came from social media /

internet as much as 38\%, followed by health workers as much as $26 \%$, from television and newspapers as much as $22 \%$ and $14 \%$. 
Public Perception of Dental Health Care during the Covid-19 Pandemic using Teledentistry Surveys

Table4. Distribution of public knowledge on dental care problems during the COVID-19 pandemic $(n=50)$

\begin{tabular}{|c|c|c|c|c|}
\hline \multirow{3}{*}{ Question } & \multicolumn{4}{|c|}{ Answer } \\
\hline & \multicolumn{2}{|c|}{ Yes } & \multicolumn{2}{|c|}{ No } \\
\hline & $\mathbf{n}$ & $\%$ & $\mathbf{n}$ & $\%$ \\
\hline $\begin{array}{l}\text { 1. Are you afraid of going to a clinic or dentist's office } \\
\text { during the COVID-19 pandemic? }\end{array}$ & 44 & $88 \%$ & 6 & $12 \%$ \\
\hline $\begin{array}{l}\text { 2. In your opinion, can someone get the Coronavirus if } \\
\text { they do dental work during the COVID-19 pandemic at a } \\
\text { clinic or dentist's practice? }\end{array}$ & 50 & $100 \%$ & & \\
\hline $\begin{array}{l}\text { 3. Have you ever received information that a patient who } \\
\text { has undergone dental work has the Coronavirus? }\end{array}$ & 15 & $30 \%$ & 35 & $70 \%$ \\
\hline $\begin{array}{l}\text { 4. Dentists carry out dental care according to Standard } \\
\text { Operating Procedures, did you still not go to a dental doctor } \\
\text { during a pandemic, even though you had problems? }\end{array}$ & 34 & $68 \%$ & 16 & $32 \%$ \\
\hline
\end{tabular}

Table 4 shows that $88 \%$ of respondents felt afraid to seek dental health treatment during the COVID19 pandemic, all respondents answered that they thought that someone could contract the virus during dental health care during the pandemic. But only $30 \%$ of respondents' answers did not know there was patients who contracted the COVID-19 virus during dental treatment during the pandemic. Also, they are not sure that even though they are according to standard operating procedures, only $68 \%$ are willing to perform dental care during a pandemic. Overall, only $71.5 \%$ of the community knew about dental care problems during the pandemic.

\section{Discussion}

The results showed that the majority of respondents had experienceddentaland oralhealth problemsduring the COVID-19 pandemic, most of the respondents reported experiencing dental and oral health problems or Recurrent Apthous Stomatitis (RAS) by $26 \%$. Canker sores or recurrent apthous stomatitis is a common disease, characterized by repeated pain and ulceration of the oral mucosal tissues that move or are not keratinized. The results of previous studies suggest that disorders of the natural and adaptive immune systems that are genetically mediated play an important role in the development of this disease. The high incidence of thrush can be associated with increased anxiety and stress during the COVID19 pandemic. SARS-COV-2 transmission during dental procedures can occur through inhalation of aerosol/droplets from an infected person or direct contact with contaminated mucous membranes and instrument surfaces. This causes a fairly high risk for dental practitioners to face the risk of the
Coronavirus [20]. Respondents, 'opinion that dentists are at a high risk of virus transmission due to saliva exposure and aerosol-producing practices. This is according to the opinion of Izetti $\mathrm{R}$ et al., dentists are at a high risk of transmitting the coronavirus due to exposure to saliva and aerosol production during dental care procedures [10]. To improve individual health and public health status to avoid COVID-19, efforts to increase awareness of the risk of COVID-19 transmission can be carried out, especially making changes in people's behavior to a new normal. In light of the current COVID-19 pandemic, social media service providers are crucial for disseminating information about COVID-19 around the world. Of the $74 \%$ of study subjects who obtained information from social media about the risk of transmitting COVID19 through dental care, $26 \%$ obtained information directly from health workers. The dissemination of information on social media be very fast and can help the public on the importance of maintaining health, but the question is whether social media spreads information or misinformation to the public regarding the Covid-19 virus [18]. This agrees that the internet and social media are currently considered as a means of searching for health information [21]. However, social media also has its drawbacks, such as being a medium for spreading rumors and misinformation that can create panic and confusion. So public policy must consider the communication strategy because it has the risk of affecting psychologically and it is expected that the public will comply with public control measures by the government. In general, the coronavirus is transmitted in two ways, namely through direct transmission (coughing, sneezing and droplet inhalation) and contact transmission (contact 
Public Perception of Dental Health Care during the Covid-19 Pandemic using Teledentistry Surveys

with mucous membranes in the mouth, nose, and eyes. As for dentistry, COVID-19 is likely to spread through the air, contact, and contaminated surfaces. The results of the study regarding knowledge about transmission of COVID-19 through dental care in this study were to answer that, "the risk of coronavirus transmission is when touching objects / the environment around the clinic/dentist's practice affected by the droplets of patients infected with the coronavirus" (62\%). The results of this study are in line with other studies that state that "the route of the spread of the coronavirus is through touching an object or surface that has been in contact with a patient infected with the coronavirus" [22] [23].The problems experienced by respondents during the COVID-19 pandemic to overcome dental and oral health problems during the pandemic were $62 \%$ "taking action on their own", and only $12 \%$ of respondents went to a dentist. The high percentage of subjects who perform their actions is supported by data from the Basic Health Research of the Ministry of Health of the Republic of Indonesia (RISKESDAS 2018), the proportion of Indonesians who have dental and oral health problems is 29.8\% [24]. However, the overall proportion of the population receiving treatment in Indonesia is only 29.6\%. During the COVID-19 pandemic, people were afraid to do dental care as much as $88 \%$, this is in accordance with research reported by Zeggara at $70.2 \%$ [25]Based on research conducted by Guo, et al. in China [7], the number of people who came to the dentist for non-urgent dental care during the COVID-19 pandemic decreased compared to the preCOVID-19 period. Similar results were obtained in this study. This is due to government regulations that limit the types of a dental and oral health services that can be carried out in dentist practices and clinics, and the high level of public fear of COVID-19 transmission. In this study, $16 \%$ of respondents who had dental and oral health problems chose to consult online with a dentist, and 10\% called their dentist during the COVID-19 pandemic. Many experts in health communication and teledentistry technology believe that telehealth services are services that can narrow the distance between communities, doctors, and health care providers. This allows everyone to stay in their home while communicating about their dental health problems [13] [16].

In this study, as many as $68 \%$ chose not to visit a dentist clinic / practice during the COVID-19 pandemic even though if the dentist performed dental treatment in accordance with Standard Operating Procedures,

Archives of Dentistry and Oral Health V3 . I2 . 2020 in this case the use of complete APD and as many as 16 people ( $32 \%$ ) choose to perform dental work in a dentist's practice / clinic if the dentist performs dental treatment according to Standard Operating Procedures. A study from Wuhan, China, the epicenter of the pandemic, showed that while SARS-CoV-2 infection did occur in a small proportion of dental professionals, the use of masks and handscoens could effectively prevent further spread of infection among peers in close contact. The study states that dental services should wear adequate APD when providing emergency dental services, including N95 masks, gloves, isolation gowns, eye protection, face protection, and head and shoe covers [26] [27]. Such personal protective measures are effective, as no patient-tohealth transmission has been reported in China.

In dentistry, there are three critical categories of tools, including critical tools (surgical instruments, needles, burs, and probes), semi-critical tools (mouth glasses, trays, prosthetic products), and non-critical tools (X-ray cones, facials). arch, bleaching lamp, extraoral camera). Apartfrom tools, surfaces are also categorized into semi-critical surfaces (dental chairs, handpieces, scalers, handles, and lamps) and non-critical surfaces (floors, furniture surfaces) [11]. Both critical, semicritical, non-critical and semi-critical and non-critical surfaces each have a high risk of contamination by microorganisms during dental procedures. Therefore, to reduce the risk of cross-infection COVID-19 in clinics dental care, it is necessary to disinfect critical, semi-critical, and non-critical equipment using disinfection that is effective against COVID-19. Some precautions during dental care other than following the Health protocol that has been instructed, namely using a solution of povidone-iodine (PVP-I) products [28] [29].

When conducting this research, several obstacles were found such as respondents who were willing to be interviewed could not be generalized to present the population as a whole, because it tended to be followed only by respondents who were interested in the survey topic.

Another limitation is that this study cannot be used to represent the population in the South Sulawesi province. Also, this suspension is only the determination of the number of samples based on a certain time span. In addition, the response rate in the survey is lower than that of other surveys. There were several things that caused the low response rate 
Public Perception of Dental Health Care during the Covid-19 Pandemic using Teledentistry Surveys

in the survey, including concerns about confidentiality that made some potential respondents reluctant to conduct interviews.

\section{CONCLUSION}

Public perception about dental care during the COVID19 pandemic is quite good, people experience dental health problems as much as $88 \%$ and do self-care as much as $46 \%$. The public believes that having dental care during a pandemic will result in contracting the coronavirus.

\section{REFERENCES}

[1] Lai, Alex L Millet, Jean K Daniel, Susan Freed, Jack H Whittaker, Gary R, “Since January 2020 Elsevier has created a COVID-19 resource centre with free information in English and Mandarin on the novel coronavirus COVID- company 's public news and information website. Elsevier hereby grants permission to make all its COVID19-r," the Lancet, vol. 395, no. April, p. 1315, 2020.

[2] Del Rio, Carlos Malani, Preeti N., "COVID-19 New Insights on a Rapidly Changing Epidemic," JAMA - Journal of the American Medical Association, vol. 323, no. 14, pp. 1339-1340, 2020.

[3] Peng, Xian Xu, Xin Li, Yuqing Cheng, Lei Zhou, Xuedong Ren, Biao, "Transmission routes of 2019-nCoV and controls in dental practice," International Journal of Oral Science, vol. 12, no. 1, pp. 1-6, 2020.

[4] Ather, Amber Patel, Biraj Ruparel, Nikita B. Diogenes, Anibal Hargreaves, Kenneth M., “Coronavirus Disease 19 (COVID-19): Implications for Clinical Dental Care," Journal of Endodontics, vol. 46, no. 5, pp. 584-595, 2020.

[5] Chang, De Lin, Minggui Wei, Lai Xie, Lixin Zhu, Guangfa Dela Cruz, Charles S. Sharma, Lokesh, "Epidemiologic and Clinical Characteristics of Novel Coronavirus Infections Involving 13 Patients Outside Wuhan, China," JAMA - Journal of the American Medical Association, vol. 323, no. 11, pp. 1092-1093, 2020.

[6] Siegel, Karolynn Schrimshaw, Eric W. Kunzel, Carol Wolfson, Natalie H. Moon-Howard, Joyce Moats, Harmon L. Mitchell, Dennis A., "Types of dental fear as barriers to dental care among African American adults with oral health symptoms in Harlem," Journal of Health Care for the Poor and Underserved, vol. 23, no. 3, pp. 1294-1309, 2020.

[7] Huaqiu Guo ay, Yin Zhou by, Xiaoqiang Liu c*, Jianguo Tan c, "Since January 2020 Elsevier has created a COVID-19 resource centre with free information in English and Mandarin on the novel coronavirus COVID- 19. The COVID-19 resource centre is hosted on Elsevier Connect, the company 's public news and information," Journal of Dental Science, vol. xxxx, p. xxx.

[8] Napimoga, Marcelo Henrique, "Dentistry vs Severe Acute Respiratory Syndrome Coronavirus 2 : Como enfrentar o inimigo," RGO, Rev Gaúch Odontol., 2020.

[9] Bizzoca, Maria Eleonora Campisi, Giuseppina Muzio, Lorenzo Lo, "Covid-19 Pandemic: What Changes for Dentists and Oral Medicine Experts? A Narrative Review and Novel Approaches to Infection Containment.," nternational journal of environmental research and public health, vol. 17, no. 11, pp. 1-31, 2020.

[10] Izzetti, R. Nisi, M. Gabriele, M. Graziani, F., "COVID-19 Transmission in Dental Practice: Brief Review of Preventive Measures in Italy," Journal of Dental Research, pp. 1-9, 2020.

[11] Spicciarelli, V Marruganti, C Viviano, M Baldini, N Franciosi, G Tortoriello, M Grandini, S, "Prevention and safety in the dental office after Novel Human Coronavirus outbreak: unresolved questions and future directions," Journal of Osseointegration, vol. 12, no. 2, pp. 155-164, 2020.

[12] Wu, Fan Zhao, Su Yu, Bin Chen, Yan Mei Wang, Wen Song, Zhi Gang Hu, Yi Tao, Zhao Wu Tian, Jun Hua Pei, Yuan Yuan Yuan, Ming Li Zhang, Yu Ling Dai, Fa Hui Liu, Yi Wang, Qi Min Zheng, Jiao Jiao Xu, Lin Holmes, Edward C. Zhang, Yong Zhen, "A new coronavirus associated with human respiratory disease in China," Nature, vol. 579, no. 7798, pp. 265-269, 2020.

[13] Gadzinski, Adam J. Andino, Juan J. Odisho, Anobel Y. Watts, Kara L. Gore, John L. Ellimoottil, Chad, "Telemedicine and eConsults for Hospitalized Patients During COVID-19," Urology, pp. 1-3, 2020.

[14] Almazrooa, Soulafa A. Mansour, Ghada A. Alhamed, Sana A. Ali, Sarah A. Akeel, Sara K. Alhindi, Nada A. Felemban, Osama M. Mawardi, Hani H. Binmadi, Nada O., "he application of teledentistry for Saudi patients' care: A national 
Public Perception of Dental Health Care during the Covid-19 Pandemic using Teledentistry Surveys

survey study," Journal of Dental Sciences, no. xxxx, 2020.

[15] Fricton, James Chen, Hong, “Using Teledentistry to Improve Access to Dental Care for the Underserved," Dental Clinics of North America, vol. 53, no. 3, pp. 537-548, 2009.

[16] Daniel, Susan J. Kumar, Sajeesh, "Teledentistry: A key component in access to care," Journal of Evidence-Based Dental Practice, vol. 14, no. SUPL, pp. 201-208, 2014.

[17] "Behavioral Risk Factor Surveillance System Questionnaire Behavioral Risk Factor Surveillance System 2012 Questionnaire Table of Contents," Centers for Disease Control and Prevention, pp. 1-64, 2016.

[18] R, Jayaseelan D, Brindha Waran, Kades, "Social Media Reigned by Information or Misinformation About COVID-19: A Phenomenological Study," SSRN Electronic Journal, 2020.

[19] Kamate, Shivalingesh Krishnappa Sharma, Swati Thakar, Sahil Srivastava, Divya Sengupta, Kaushikee Hadi, Ahmed Jhurry Chaudhary, Alankrita Joshi, Ruby Dhanker, Kuldeep, "Assessing knowledge, attitudes and practices of dental practitioners regarding the covid-19 pandemic: A multinational study," Dental and Medical Problems, vol. 57, no. 1, pp. 11-17, 2020.

[20] Ahorsu, Daniel Kwasi Lin, Chung Ying Imani, Vida Saffari, Mohsen Griffiths, Mark D Pakpour, Amir H, "The Fear of COVID-19 Scale: Development and Initial Validation," International Journal of Mental Health and Addiction, 2020.

[21] Bao, Yanping Sun, Yankun Meng, Shiqiu Shi, Jie Lu, Lin, "2019-nCoV epidemic: address mental health care to empower society," The Lancet, vol.
395, no. 10224, pp. e37-e38, 2020.

[22] Devaraj, C. G. Eswar, Pranati, "Reasons for use and non-use of dental services among people visiting a dental college hospital in India: A descriptive cross-sectional study," European Journal of Dentistry, vol. 6, no. 4, pp. 422-427, 2012.

[23] Deep, Kanwar Nanda, Singh Nanda, Jasmine, "Recommendations and Management in Dental Practice during Coronavirus".

[24] Riskesdas, "Riset Kesehatan Dasar 2018," Kementrian Kesehatan Republik Indonesia, 2018.

[25] Zegarra-Valdivia, Jonathan Chino Vilca, Brenda Nadia Ames-Guerrero, Rita Judith, "Knowledge, perception and attitudes in Regard to COVID19 Pandemic in Peruvian Population," no. April, 2020.

[26] Geldsetzer, Pascal, "Using rapid online surveys to assess perceptions during infectious disease outbreaks: a cross-sectional survey on Covid-19 among the general public in the United States and United Kingdom.," medRxiv : the preprint server for health sciences, 2020.

[27] Meng, L. Hua, F. Bian, Z., "Coronavirus Disease 2019 (COVID-19): Emerging and Future Challenges for Dental and Oral Medicine," ournal of Dental Research, vol. 99, no. 55, pp. 481-487, 2020.

[28] Kariwa, Hiroaki Fujii, Nobuhiro Takashima, Ikuo, "Inactivation of SARS Coronavirus by Means of Povidone-Iodine, Physical Conditions and Chemical Reagents Hiroaki," Dermatology, vol. 212, p. 119-123, 2006.

[29] Matthews, Camesia 0, "The Benefits of Preoperational Oral Rinsing during and after the Novel Coronavirus Pandemic," National Dental Association White Paper, no. April, pp. 1-9, 2020.

Citation: Burhanuddin Daeng Pasiga. Public Perception of Dental Health Care during the Covid-19 Pandemic using Teledentistry Surveys. Archives of Dentistry and Oral Health. 2020; 3(2): 20-27.

Copyright: (C) 2020 Burhanuddin Daeng Pasiga. This is an open access article distributed under the Creative Commons Attribution License, which permits unrestricted use, distribution, and reproduction in any medium, provided the original work is properly cited. 